\title{
Methodological limitations of an etiological framing of Ariarathes' goitre: response to Tekiner et al.
}

\author{
F. M. Galassi ${ }^{1} \cdot$ R. Gelsi ${ }^{1}$
}

Received: 3 March 2015 / Accepted: 4 March 2015 / Published online: 2 April 2015

(C) Italian Society of Endocrinology (SIE) 2015

To the Editor-in-Chief,

In a recent article published in this journal, Tekiner et al. [1] presented a most interesting example of retrospective diagnosis based on the recognition of a pathological trait in artistic representations. King Ariarathes IV Eusebes of Cappadocia is diagnosed with goitre using a coin minted in the 33rd year of his reign on whose obverse the king's neck shows a dramatically enlarged anterior compartment. While the proposed diagnosis is undoubtedly correct and highly suggestive of thyroid pathology, we would like to point out that a stylized representation of the king's traits may not be enough to venture into the field of aetiology. In particular, building on the fact that the coin was minted in $187 \mathrm{BC}$ (after 33 years of reign) in Mazaka, the authors interestingly endeavour to establish a causal link between the location of the king's new capital (i.e., Mazaka) and the development of the disease, since the region in question is mountainous, and almost as a rule, mountainous regions are characterized by endemic iodine deficiency. Although such an interpretation may well be correct, to formulate an even more solid hypothesis, more data regarding the actual extent of iodine deficiency in that particular region in that historical period together with descriptions of Ariarathes' behaviour and symptoms in ancient literary sources, potentially consistent with a diagnosis of hypothyroidism, would be essential.
In conclusion, the effort by Tekiner et al. to diagnose Ariarathes IV with goitre from an artistic representation is very commendable and it follows in the footsteps of an established pathographic tradition. Nevertheless, more interdisciplinary research may be necessary to provide compelling evidence for the origin of Ariarathes' disease. On account of this, this letter is meant to encourage the authors, as well as all scholars interested in the life and character of the Cappadocian monarch, to develop this preliminary study into a full research paper, from whose scientific worth both classicists and medical humanists would certainly benefit.

Conflict of interest The authors declare no conflicts of interest.

Ethical approval This article does not contain any studies with human participants or animals performed by any of the authors.

Informed consent No informed consent.

\section{Reference}

1. Tekiner H, Erkiletlioglu H, Kelestimur F (2015) King Ariarathes IV of Cappadocia: coins reveal enlarged thyroid (188 BC). J Endocrinol Invest 38:261-262
F. M. Galassi

francesco.galassi5@studio.unibo.it

1 University of Bologna, Bologna, Italy 